BIOMEDICAL AND BIOSOCIAL ANTHROPOLOGY
$\begin{gathered}\text { Official Journal of the International Academy } \\ \text { of Integrative Anthropology } \\ \text { journal homepage: http://bba-journal.com }\end{gathered}$

\title{
Cognitive disorders in patients after cardiac surgery
}

Belinskyi A. V. ${ }^{1}$, Rasputina L. V. ${ }^{2}$, Mostovoy Y. M. ${ }^{2}$, Mostova O. P. ${ }^{2}$, Danilevych T. D. ${ }^{2}$

${ }^{1}$ Vinnytsia Regional Center of Cardiovascular Pathology, Vinnytsya, Ukraine

${ }^{2}$ National Pirogov Memorial Medical University, Vinnytsya, Ukraine

\section{ARTICLE INFO}

Received: 2 October 2020

Accepted: 30 October 2020

UDC: $616.831-005: 616.12-089$

CORRESPONDING AUTHOR

e-mail: danilevychtd@gmail.com Danilevych T. D.

\begin{abstract}
The occurrence of cognitive disorders is a common problem after surgery. The degree of worsening of cognitive functions after surgery and anesthesia has a significant impact on the patient's health and is significantly associated with prolonged recovery in the hospital, increased morbidity and delayed functional recovery. The aim of the study was to increase the effectiveness of the diagnosis of moderate cognitive impairment and to determine its gender and age characteristics in patients before and after cardiac surgery in the early postoperative period ( 3 and 7 days). We examined 56 patients who underwent cardiac surgery for coronary heart disease in 37 (66.1\%) and valvular heart defects in 19 (33.9 \%) patients. Assessment of cognitive functions was performed before surgery, on the 3rd and 7th day of the postoperative period. Testing was performed using the Montreal Cognitive Test. Statistical processing of the obtained data was performed on a personal computer using the statistical software package SPSS 12.0 for Windows using parametric and non-parametric methods. It was found that presence of cognitive disorders before surgery was registered in 37 (66.1\%) patients, mostly among the age of group of 60-74 years and had no gender difference. It was found that in the early postoperative period there is a significant worsening of cognitive functions in patients after cardiac surgery on 3rd day - in 45 (80.4\%), on 7th day - in 44 (78.6\%) patients, respectively.

Keywords: cognitive disorders, Montreal cognitive test, cardiovascular diseases, cardiac surgery, coronary heart disease.
\end{abstract}

\section{Introduction}

Despite the improvement of surgical techniques and the implementation of effective brain protection strategies, the incidence of moderate cognitive impairment (CD) after cardiac surgery has remained relatively stable for many years. It is established that the frequency of $C D$ in $1-3$ months after cardiac surgery is from $10-16 \%$ to $40 \%$ [6, $12,17]$. Most studies show a decrease in its severity over time from 3 months to 1 year after surgery $[6,14]$.

The occurrence of postoperative cognitive dysfunction is associated with a combination of factors often associated with artificial circulation: embolism, hypoperfusion and inflammatory response [2]. However, not only these factors and their potential brain effects can lead to CD. It is known that such disorders occur in patients who underwent heart surgery without artificial circulation, as well as those who underwent transcatheter interventions. There is evidence that vascular risk factors play an important role in the development of both early and late postoperative cognitive dysfunction [4]. According to A. C. Sauer et al. [22] delirium after cardiac surgery is independently associated with decreased cognitive function 1 month after surgery, but cognitive performance is usually restored within 1 year. Patients with a predisposition to CD can be identified before surgery due to worse results in the task of checking attention.

It should be noted that postoperative cognitive changes in adults are superimposed on normal age-related neurophysiological changes [26]. Thus, it is important to compare postoperative cognitive changes with those observed before surgery, according to risk factors for decreased cognitive function. It was found that the thickness of the intima-media complex of the internal carotid artery, but not the intima-media of the common carotid artery, was associated with a higher prevalence of silent cerebral infarctions, large hyperintensive areas of white matter, lower total brain volume and lower verbal memory productivity and nonverbal memory performance [19]. 
Cognitive dysfunction is relatively common in patients with chronic heart failure ( $\mathrm{CHF}$ ), the deficiency is most pronounced in the areas of executive function, memory, speech and mental speed. It was found that $25 \%$ of patients with CHF had cognitive deficits, compared with $15 \%$ of patients with cardiovascular disease (CVD) uncomplicated $\mathrm{CHF}$ and $4 \%$ of healthy individuals. Independent risk factors for $C D$ in patients with CHF are intelligence, functional class (FC) of $\mathrm{CHF}$ and the presence of apolipoprotein (Apo) E allele $\varepsilon 4$ [25]. One study assessed cognitive function depending on the severity of CHF. Severe cognitive impairment was present in $9.2 \%$ of patients, but only $20 \%$ of them had dementia. Cognitive dysfunction was more common in patients with FC IV than with FC II $\mathrm{CHF}$. Changes in the severity of $\mathrm{CHF}$ were not associated with changes in the severity of cognitive disorders [9].

A number of authors report the association of cognitive impairment with chronic kidney disease. U. E. Williams et al. [27] found that the majority of patients (53.2\%) with stage 3-5 CKD have moderate cognitive impairment compared to the control group.

A recent study [20] suggests that pre-existing coronary heart disease (CHD) is associated with an accelerated decline in cognitive function. The study included 7888 patients who underwent cognitive assessment at the beginning of follow-up (2002 - 2003) and again in one of the periods (2004 - 2005) or (2016 - 2017) and did not have a history of coronary heart disease. The coronary heart disease incident was identified as a diagnosis of myocardial infarction (MI) and/or angina pectoris during follow-up. The results showed that coronary heart disease is associated with an accelerated decline in cognitive function during the median follow-up of 12 years. The annual progression of CD does not differ between groups with verified coronary heart disease and individuals without coronary heart disease. There was no short-term decrease in cognitive function immediately after the MI incident. Over the years since the diagnosis of coronary heart disease, global cognition, verbal memory, and temporal orientation have declined significantly faster than before the MI/angina incident.

Many researchers have used pre- and postoperative neuropsychological testing to assess cognitive dysfunction after cardiovascular surgery. It is known that for most people, performance improves with retesting at short intervals. Several methods can explain this learning effect and the internal variability of retesting [3]. Some tests have "floor" or "ceiling" effects that reduce the sensitivity to detect cognitive changes in patients with high or low baseline cognitive function. For example, the Trail Making Test (Part B) has a high sensitivity to detecting cognitive impairment in patients with high levels of cognitive function, but has a reduced sensitivity to detecting disorders in patients with severe preoperative cognitive impairment [18]. In contrast, the Mini Mental Status Examination has a "ceiling" effect in cognitively healthy people, but is sensitive to cognitive changes in patients with mild cognitive dysfunction [8]. It is also important to consider the timing of pre- and postoperative testing. Cognitive dysfunction in the early postoperative period is likely to be affected by postoperative pain, the use of narcotic analgesics and acute postoperative recovery [7].

It is important for clinical practice to use simple and reliable tools to help clinicians assess the risk of cognitive change and identify individuals who need closer monitoring, prevention, and possibly additional treatment.

The aim of the work is to increase the efficiency of diagnosis of moderate cognitive impairment and to determine its sex and age characteristics in patients before and after cardiac surgery in the early postoperative period (3 and 7 days).

\section{Materials and methods}

56 patients were examined, including 19 (33.9\%) men and $37(66.1 \%)$ women $(p=0.02)$. The age of patients ranged from 31 to 79 years, with an average of $60.86 \pm 8.87$ years. The gradation by age showed that the group younger than 45 years included $2(3.2 \%), 45-59$ years $-20(32.3 \%)$, $60-74$ years $-31(50.0 \%), 75-90$ years $-3(4.8 \%)$ patient accordingly.

Cardiac surgery was performed for coronary heart disease in $37(66.1 \%)$ and valvular heart defects in 19 $(33.9 \%)$ patients $(p=0.02)$. The duration of the operation ranged from 240 to 600 minutes, averaging $371.9 \pm 102.0$ minutes. In 25 (44.6\%) cases, operations were performed in the conditions of artificial circulation (AC) - bypass, the average duration of which did not differ from operations without $A C(389.4 \pm 116.9$ vs. $355.5 \pm 86.2, p=0.34)$.

The most common comorbidity in the examined patients was hypertension (HT), it was diagnosed in $45(80.4 \%)$ people, including $15(33.3 \%)$ women and 30 (66.7\%) men $\left(x^{2}=0.036, p=0.84\right)$.

Analyzing the severity of $\mathrm{HT}$, it was found that $5(8.9 \%)$ patients had stage 1, $16(28.6 \%)$ had stage 2, 24 (42.9\%) had stage 3 , and $7(12.5 \%)$ had stage 1, $14(25.0 \%)-2$ degree, in $24(42.9 \%)-3$ degree of HT respectively. The average duration of HT was $7.91 \pm 7.35$ years. The course of $\mathrm{HT}$ in $17(37.7 \%)$ patients was uncontrolled, in 28 $(62.3 \%)$ - controlled, respectively $\left(x^{2}=2.928, p=0.09\right)$. Analyzing sex features, the controlled course of HT was in $6(31.6 \%)$ women and $10(27.0 \%)$ men, respectively $\left(x^{2}=0.572, p=0.449\right)$. The risk of cardiovascular complications in $1(1.8 \%)$ - low, $7(12.5 \%)$ - moderate, in $20(35.7 \%)$ - high and in $28(50.0 \%)$ patients - very high.

Thyroid diseases were observed in - 9 (16.1\%), oncological diseases - $3(5.4 \%)$, diseases of the gastrointestinal tract (GI tract) - $31(55.4 \%)$, gout - 3 (5.4\%), diabetes mellitus (DM) - 7 (12.5\%), diseases of the musculoskeletal system - 3 (5.4\%), chronic obstructive pulmonary disease/bronchial asthma - $7(12.5 \%)$ patients, respectively. CHF I FC were observed in $4(7.1 \%)$, II FC - in $13(23.2 \%)$, III FC - in $38(67.9 \%)$, IV FC - in $1(1.8 \%)$ 
Table 1. Analysis of the distribution of probable risk factors for cognitive impairment.

\begin{tabular}{|l|c|}
\hline \multicolumn{1}{|c|}{ Factors } & $\begin{array}{c}\text { Proportion of } \\
\text { patients }(\mathrm{n}, \%)\end{array}$ \\
\hline $\begin{array}{l}\text { Signs of structural remodeling of the carotid } \\
\text { arteries }\end{array}$ & $44(78.6 \%)$ \\
\hline Dyslipidemia & $23(41.1 \%)$ \\
\hline $\begin{array}{l}\text { Acute cerebrovascular accident (ACA) in the } \\
\text { anamnesis }\end{array}$ & $3(5.4 \%)$ \\
\hline Ml in the anamnesis & $20(35.7 \%)$ \\
\hline Atrial fibrillation & $17(30.4 \%)$ \\
\hline Glomerular filtration rate $<60 \mathrm{ml} / \mathrm{min} / 1.72 \mathrm{~m}^{2}$ & $22(39.3 \%)$ \\
\hline
\end{tabular}

patients, respectively. According to echocardiographic examination, $40(71.4 \%)$ patients had preserved left ventricular systolic function (ejection fraction (EF) $>50 \%$ ), $9(16.1 \%)$ had intermediate EF (40-50\%), and 7 (12.5\%) reduced EF (<40\%). Obesity - in $15(26.8 \%)$ patients, among them in $11(19.6 \%)$ - stage 1 , in $3(5.4 \%)$ - stage 2 , in 1 (1.8 $\%)$ - stage 3 obesity, respectively.

According to coronary angiography in 5 (8.9\%) patients revealed lesions of 1 coronary artery (CA), in $5(8.9 \%)-2$ branches of CA, in $27(48.2 \%)-3$ branches of CA, in 19 $(33.9 \%)$ - vascular lesions was not detected.

We also analyzed the probable causes of cognitive impairment in patients who underwent cardiac surgery (Table 1).

It should be noted that $44(78.6 \%)$ patients already had signs of structural remodeling of the carotid arteries (in the case of atherosclerotic plaques in the carotid arteries and/ or intima-media thickness (IMT) $>0.9 \mathrm{~mm}$ and/or blood flow rate $>1.2 \mathrm{~m} / \mathrm{s}), 20(35.7 \%)$ patients had a history of MI, 3 (5.4 $\%)$ - ACA, respectively. Signs of dyslipidemia were observed in $23(41.1 \%)$ patients. Decreased glomerular filtration rate (GFR) less than $60 \mathrm{ml} / \mathrm{min} / 1.72 \mathrm{~m}^{2}$ was observed in 22 (39.3 $\%$ ) patients. The average GFR (according to the formula CKD-EPI) was $60.71 \pm 15.09 \mathrm{ml} / \mathrm{min} / 1.72 \mathrm{~m}^{2}$.

Atrial fibrillation (AF) is present in $17(30.4 \%)$ patients, among them - in $5(8.9 \%)$ paroxysmal, in $6(10.7 \%)$ persistent and in $6(10.7 \%)$ - permanent form of AF. The average score on the scale CHA2DS2VASc was $2.410 \pm 0.870$.

Analyzing the sex and age characteristics of patients (Table 2) who underwent cardiac surgery, it was found that women were older than men (65.84 vs. $58.30, p=0.002)$, more often had thyroid disease $(31.6 \%$ vs. $8.1 \%, p=0.02)$, there is a history of acute cerebrovascular accident (ACA) stroke $(15.7 \%$ vs. $0 \%, p=0.01)$. In turn, more than half of men had diseases of the gastrointestinal tract $(64.9 \%$ vs. $36.8 \%, p=0.04)$.

Assessment of cognitive functions was performed before surgery, on the 3rd and 7th day of the postoperative period. Testing was performed using the Montreal Cognitive Test (MOCA). The MOCA test is a quick tool for screening for cognitive deficits [https://www.mocatest.org]. It is highly sensitive $(90 \%)$ and specific (87\%) for detecting people with cognitive disorders [11]. This test is recommended for use in people aged $55-85$ years.

The test was performed by a cardiologist who had previously been trained in the methodology, evaluation and interpretation of the MOCA test (online) and received a certificate, which is mandatory for the use of this questionnaire. The time of the MOCA test is short (approximately 10 minutes), which did not cause discomfort or a negative attitude of the patient. Testing includes 12 stages, which allows you to assess the various cognitive functions of the patient: attention, concentration, executive functions, memory, language, visual and constructive skills, abstract thinking, arithmetic and orientation. The maximum possible result is 30 points. A score of 26 or higher is considered normal, $18-25$ is mild, $10-17$ is moderate, and less than 10 is severe cognitive impairment. To the total score, add 1 point if the education is less than 12 years and 2 points if the patient's education is less than 10 years [https://www.mocatest.org].

Statistical processing of the obtained data was performed on a personal computer using the statistical software package SPSS 12.0 for Windows. Quantitative data (with normal distribution of characteristics) are presented in the form $(M \pm \sigma)$, where $M$ is the average value of the sample, and $\sigma$ is the standard deviation. The reliability of the difference in quantitative values was calculated according to Student's criterion, the percentage $-X^{2}$, the dynamics of indicators was estimated by $X^{2}$ by the method of McNemar.

Table 2. Sex and age characteristics of the examined patients.

\begin{tabular}{|l|c|c|c|c|}
\hline \multicolumn{1}{|c|}{ Parameters } & $\begin{array}{c}\text { Men (1) } \\
(\mathrm{n}=37)\end{array}$ & $\begin{array}{c}\text { Women }(2) \\
(\mathrm{n}=19)\end{array}$ & $\begin{array}{c}\text { Total } \\
(\mathrm{n}=56)\end{array}$ & $p_{1-2}$ \\
\hline $\begin{array}{l}\text { Average age, } \\
\text { years }\end{array}$ & $58.30 \pm 8.29$ & $65.84 \pm 7.93$ & $60.86 \pm 8.86$ & $=0.002$ \\
\hline $\begin{array}{l}\text { Hypertensive } \\
\text { disease }\end{array}$ & $30(81.0 \%)$ & $15(78.9 \%)$ & $45(80.3 \%)$ & $=0.84$ \\
\hline $\begin{array}{l}\text { Uncontrolled } \\
\text { course of } \\
\text { hypertensive } \\
\text { disease }\end{array}$ & $7(18.9 \%)$ & $10(52.6 \%)$ & $40(64.5 \%)$ & $=0.45$ \\
\hline Type Il diabetes & $4(10.8 \%)$ & $3(15.7 \%)$ & $7(12.5 \%)$ & $=0.59$ \\
\hline Atrial fibrillation & $9(24.3 \%)$ & $8(42.1 \%)$ & $17(30.4 \%)$ & $=0.17$ \\
\hline $\begin{array}{l}\text { Average score } \\
\text { on the scale } \\
\text { CHA }{ }_{2} \text { DS }\end{array}$ VASc & $2.330 \pm 0.866$ & $2.500 \pm 0.926$ & $2.410 \pm 0.870$ & $=0.7$ \\
\hline Obesity & $8(21.6 \%)$ & $7(36.8 \%)$ & $15(26.7 \%)$ & $=0.22$ \\
\hline $\begin{array}{l}\text { Diseases of the } \\
\text { thyroid gland }\end{array}$ & $3(8.1 \%)$ & $6(31.6 \%)$ & $9(16.1 \%)$ & $=0.02$ \\
\hline ACA & 0 & $3(15.7 \%)$ & $3(5.35 \%)$ & $=0.01$ \\
\hline Ml & $14(37.8 \%)$ & $6(31.5 \%)$ & $16(25.8 \%)$ & $=0.64$ \\
\hline $\begin{array}{l}\text { Gastrointestinal } \\
\text { diseases }\end{array}$ & $24(64.9 \%)$ & $7(36.8 \%)$ & $31(55.4 \%)$ & $=0.04$ \\
\hline
\end{tabular}

Notes: in this and subsequent tables, the reliability of the difference in quantitative values is calculated by the Student's criterion, the percentage - by the criterion $X^{2}$. 


\section{Results}

Analysis of MOCA test results showed that the mean total score before surgery was $23.25 \pm 3.16$ and did not differ between men and women ( 23.73 vs. $22.32, p=0.12$ ).

Analysis of the sex and age characteristics of $C D$ showed that the number of patients with CD before surgery was the same among both women and men. There was also no sex difference in the severity structure of the $C D$ (Table 3).

The mean age of the group of patients with pre-operative CD was $62.05 \pm 7.91$ and did not differ from the mean age of patients without CD (62.05 vs. $58.53, p=0.16)$. The distribution of patients according to age gradations (Fig. 1) showed that the largest number of patients with $C D$ was observed among the age group 60-74 years (42.9\% vs. $12.5 \%, p<0.05)$.

It was found that the average test score on the 3rd day after surgery was $22.34 \pm 4.78$. There was a tendency to a significant decrease compared to the result before surgery ( 23.25 vs. $22.34, p=0.08$ ). There was no sex difference in the results of the cognitive function questionnaire on day 3 of the postoperative period ( 22.70 vs. $21.63, p=0.43$ ).

Analysis of the distribution of the severity of $C D$ on day 3 of the postoperative period (Table 4) depending on the article showed that there was no difference between men and women.

The mean age of the group of patients with $C D$ on day 3 after surgery was $61.51 \pm 9.42$ and did not differ from the mean age of patients without CD (61.51 vs. $58.18, p=0.26)$. The distribution of patients according to age gradations (Fig. 2) showed that 2 (4.4\%) patients were under 45 years of age, $14(31.1 \%)$, and 60-74 years of age were $26(57.8 \%)$

Table 3. Gender and age characteristics of patients with existing $\mathrm{CD}$ before operation.

\begin{tabular}{|l|c|c|c|}
\hline \multicolumn{1}{|c|}{ Parameters } & Men $(\mathrm{n}=37)$ & $\begin{array}{c}\text { Women } \\
(\mathrm{n}=19)\end{array}$ & $\mathrm{p}$ \\
\hline CD available $(\mathrm{n}=37)$ & $24(64.9 \%)$ & $13(68.4 \%)$ & $=0.79$ \\
\hline Mild CR $(\mathrm{n}=33)$ & $21(56.8 \%)$ & $12(63.2 \%)$ & $=0.85$ \\
\hline Moderate CD $(\mathrm{n}=4)$ & $3(8.1 \%)$ & $1(5.3 \%)$ & $=0.85$ \\
\hline
\end{tabular}

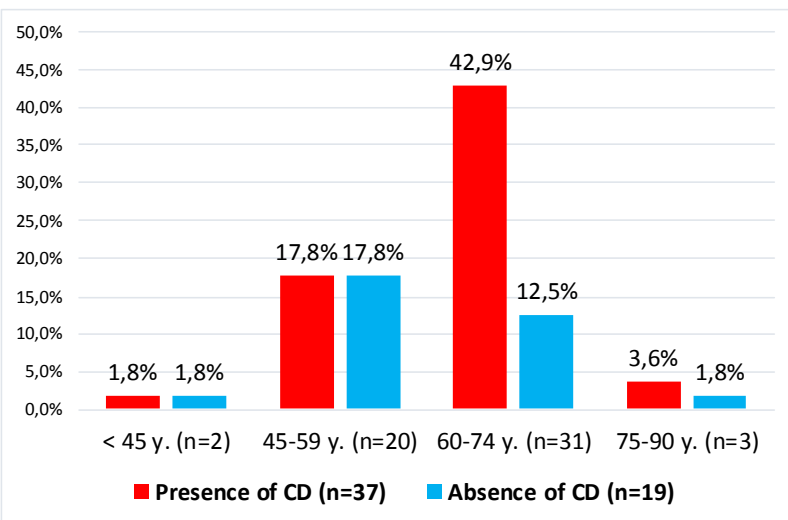

Fig. 1. Distribution of $C D$ among patients of different ages before surgery.
Table 4. Sex and age characteristics of patients with CD on day 3 of the postoperative period.

\begin{tabular}{|l|c|c|c|}
\hline \multicolumn{1}{|c|}{ Parameters } & $\begin{array}{c}\text { Men } \\
(\mathrm{n}=37)\end{array}$ & $\begin{array}{c}\text { Women } \\
(\mathrm{n}=19)\end{array}$ & $\mathrm{p}$ \\
\hline CD available $(\mathrm{n}=45)$ & $28(75.7 \%)$ & $17(89.5 \%)$ & $=0.21$ \\
\hline Mild CR $(\mathrm{n}=42)$ & $27(72.9 \%)$ & $15(79.0 \%)$ & $=0.26$ \\
\hline Moderate CD $(\mathrm{n}=3)$ & $1(2.7 \%)$ & $2(10.5 \%)$ & $=0.26$ \\
\hline
\end{tabular}

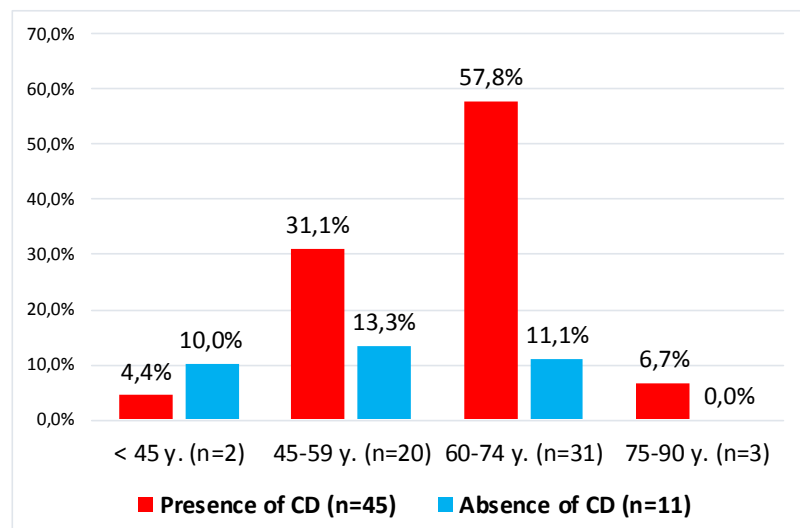

Fig. 2. Distribution of $C D$ among patients of different ages on day 3 of the postoperative period.

Table 5. Sex and age characteristics of patients with $C D$ on day 7 of the postoperative period.

\begin{tabular}{|l|c|c|c|}
\hline \multicolumn{1}{|c|}{ Parameters } & $\begin{array}{c}\text { Men } \\
(\mathrm{n}=37)\end{array}$ & $\begin{array}{c}\text { Women } \\
(\mathrm{n}=19)\end{array}$ & $p$ \\
\hline CD available $(\mathrm{n}=44)$ & $27(73.0 \%)$ & $17(89.5 \%)$ & $=0.21$ \\
\hline Mild CR $(\mathrm{n}=41)$ & $25(67.6 \%)$ & $16(84.2 \%)$ & $=0.42$ \\
\hline Moderate CD $(\mathrm{n}=1)$ & $1(2.7 \%)$ & $0(0 \%)$ & $=0.42$ \\
\hline Severe CD $(\mathrm{n}=2)$ & $1(2.7 \%)$ & $1(5.3 \%)$ & $=0.42$ \\
\hline
\end{tabular}

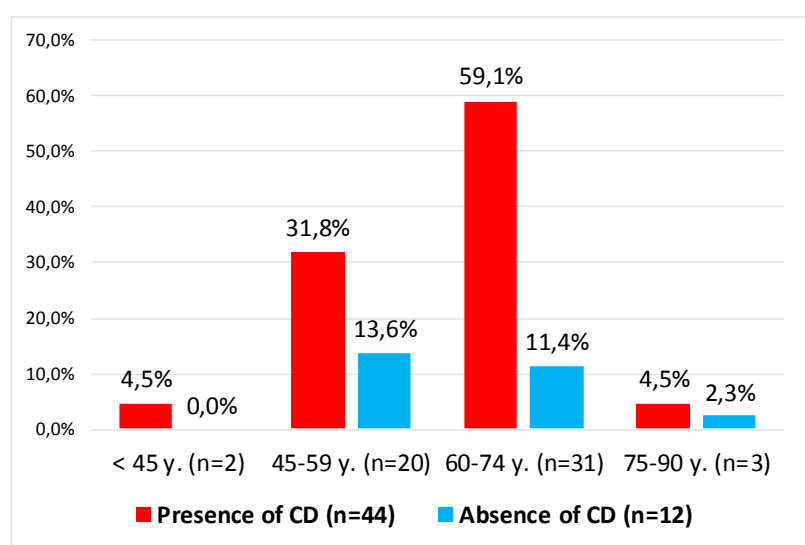

Fig. 3. Distribution of CD among patients of different ages on day 7 of the postoperative period.

and $75-90$ years $-3(6.7 \%)$ patients, respectively.

In turn, on the 7 th day after surgery, the mean score on the MOCA scale was $23.05 \pm 4.68$ and was higher than the result of the third day of the postoperative period (23.05 vs. 22.34, $p=0.01$ ), but did not differ statistically from the result before surgery ( 23.05 vs. $23.34, p=0.73)$. There was no difference in the test between men and women on day 7 


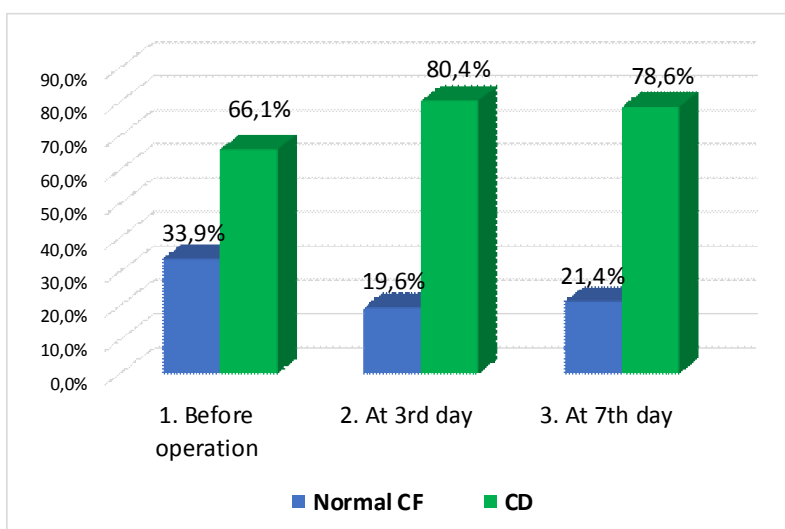

Fig. 4. Frequency of persons who had cognitive impairments during the questionnaire (before surgery, for 3 days, 7 days).

(23.16 vs. 22.84, $p=0.81$ ).

Analysis of the distribution of the severity of CD on day 7 of the postoperative period (Table 5) depending on the sex showed that there was no difference between men and women.

The mean age of the group of patients with $C D$ on day 7 after surgery was $60.82 \pm 9.10$ and did not differ from the average age of patients without $C D$ (60.82 vs. $61.00, p=0.95)$. The distribution of patients according to age gradations (Fig. 3) showed that CD among the age group younger than 45 years were in $2(4.5 \%)$ patients, 45-59 years - in 14 (31.8\%), 60-74 years - in $26(59.1 \%)$ and $75-90$ years - in 2 (4.5\%) patients, respectively.

Analyzing the dynamics of cognitive disorders in the early postoperative period (Fig. 4), it was found that the proportion of patients who already had CD before surgery was 37 $(66.1 \%)$. On the 3rd day after surgery, there was a significant increase in the proportion of patients with CD $(80.4 \%$ vs. $66.1 \%, p=0.04)$. In turn, on the 7 th day of the postoperative period, the share of patients with CD was 44 (78.6\%), which tended to be reliable compared to the data before surgery (78.6 \% vs. $66.1 \%, p=0.07$ ).

\section{Discussion}

A large amount of evidence demonstrates the relationship between the impact of surgical interventions on the course of neurocognitive functions. There are conflicting data on the effect of anesthesia on the development of long-term $C D$ in a population of patients with normal preoperative cognitive function. However, it is known that pre-operative cognitive impairment can lead to susceptibility to $C D$ progression [1] and is of scientific interest in drug selection, potential drug interactions, communication difficulties during testing, and ways to prevent and treat CD.

According to the literature, a week after cardiac surgery, cognitive decline is observed from 50 to $70 \%$ of patients [15].

One study found that coronary artery bypass grafting (CABG) using artificial circulation was complicated by shortterm and long-term neurocognitive dysfunction (96 and 55
$\%$ of cases, respectively). Also, in the early period after CABG in $68 \%$ of patients revealed a decrease in regional cerebral blood flow, and in the dynamics after 6 months - in $55 \%$ of cases [5].

L. Evered et al. [6] found that the incidence of CD on 7 day in patients after hip joint replacement surgery was $17 \%$, and after CABG - $43 \%(p<0.01)$. However, after 3 months, the incidence of $C D$ in all groups was about $17 \%(p=0.13)$ and did not depend on the nature, type of surgery or anesthetic. Risk factors for cardiovascular disease did not predict the occurrence of CD after any of the procedures.

One prospective study showed that late cognitive decline (1 to 6 years) decreased in patients who underwent CABG surgery, but the degree of this reduction did not differ from that observed in patients of the same age with coronary heart disease who were treated only with medication [23].

Q. Nguyen et al. [16] examined 197 patients who underwent CABG or valve replacement surgery, and 44 (22\%) developed postoperative delirium. The results of the study showed that postoperative delirium was associated with increased anxiety and depression at 6-9 months after undergoing cardiac surgery.

A. Itagaki and others [10] found that $34.8 \%$ of patients who underwent cardiac surgery developed postoperative delirium. A multivariate analysis, adjusted for baseline characteristics, showed that only in the group of patients who already had cognitive impairment and general weakness before surgery, there was a risk of delirium after surgery (odds ratio 7.494; $95 \%$ confidence interval 1.53936.49).

As might be expected, the timing of cognitive function testing may have an important impact on results. It is known that preoperative testing should be done before the day of surgery, as the patient is unlikely to be able to focus on cognitive tests immediately before entering the operating room. In turn, the timing of testing after surgery is contradictory. Unfortunately, there is little data on cognitive recovery after anesthesia. Clinical trials have reported testing from the actual day of surgery, a few days to weeks after surgery, and months after surgery. Postoperative CD are limited in time, so the timing of testing is an important issue and makes comparing the results somewhat difficult [24].

Perhaps the most controversial aspect of the definition of $C D$ is the degree of change, which is considered statistically or clinically significant. Several authors have criticized the high variability of this aspect. The metaanalysis showed that the available research in the field of cardiac surgery is characterized by a wide range of variability due to existing factors related to the patient (age, education, comorbidity), factors of cardiovascular surgery (hypothermia, artificial circulation, aortic compression, bleeding), physiological factors (inflammation, microembolization), intraoperative factors (anesthesia, cerebral oxygenation, hypotension), perioperative factors (drugs, sleep, complications) and postoperative factors 
(rehabilitation, depression, social support). It becomes more difficult to identify postoperative $C D$ in patients when variable measurement of cognitive function is used using various neuropsychological tests and numerous analytical criteria. In addition, it is known that re-testing at short intervals can cause a learning effect, because repeated repetition of tests increases the knowledge of the test structure, and thus the results tend to increase [21].

It was found that increasing of age, level of education (patients without higher education), the need for further surgery, postoperative infections and respiratory complications were associated with early postoperative CD. T. G. Monk et al. [13] found that independent risk factors for CD 3 months after surgery were increased age, lower level of education, a history of acute cerebrovascular accident and the presence of $C D$ at discharge. Patients

\section{References}

[1] Belrose, J. C., \& Noppens, R. R. (2019). Anesthesiology and cognitive impairment: a narrative review of current clinical literature. BMC anesthesiology, 19(1), 1-12. doi: 10.1186/ s12871-019-0903-7

[2] Berger, M., Terrando, N., Smith, S. K., Browndyke, J. N., Newman, M. F., \& Mathew, J. P. (2018). Neurocognitive function after cardiac surgery: from phenotypes to mechanisms. Anesthesiology, 129(4), 829-851. doi: 10.1097/ ALN.0000000000002194

[3] Berger, M., Nadler, J. W., Browndyke, J., Terrando, N., Ponnusamy, V., Cohen, H. J., ... \& Mathew, J. P. (2015). Postoperative cognitive dysfunction: minding the gaps in our knowledge of a common postoperative complication in the elderly. Anesthesiology clinics, 33(3), 517-550. doi: 10.1016/ j.anclin.2015.05.008

[4] Bruggemans, E. F. (2013). Cognitive dysfunction after cardiac surgery: Pathophysiological mechanisms and preventive strategies. Netherlands Heart Journal, 21(2), 70-73. doi: 10.1007/s12471-012-0347-x

[5] Chernov, V. I., Efimova, N. Y., Efimova, I. Y., Akhmedov, S. D., \& Lishmanov, Y. B. (2006). Short-term and long-term cognitive function and cerebral perfusion in off-pump and on-pump coronary artery bypass patients. European Journal of Cardiothoracic Surgery, 29(1), 74-81. doi: 10.1016/j.ejcts.2005.10.001

[6] Evered, L., Scott, D. A., Silbert, B., \& Maruff, P. (2011). Postoperative cognitive dysfunction is independent of type of surgery and anesthetic. Anesthesia \& Analgesia, 112(5), 1179-1185. doi: 10.1213/ANE.0b013e318215217e

[7] Evered, L., Silbert, B., Knopman, D. S., Scott, D. A., DeKosky, S. T., Rasmussen, L. S., ... \& Nomenclature Consensus Working Group. (2018). Recommendations for the nomenclature of cognitive change associated with anaesthesia and surgery2018. Anesthesiology, 129(5), 872-879. doi: 10.1016/ j.bja.2017.11.087

[8] Galvin, J. E., \& Sadowsky, C. H. (2012). Practical guidelines for the recognition and diagnosis of dementia. The Journal of the American Board of Family Medicine, 25(3), 367-382. doi: 10.3122/jabfm.2012.03.100181

[9] Huijts, M., Van Oostenbrugge, R. J., Duits, A., Burkard, T., Muzzarelli, S., Maeder, M. T., ... \& Brunner-La Rocca, H. P. (2013). Cognitive impairment in heart failure: results from the trial of intensified versus standard medical therapy in elderly patients with congestive heart failure (TIME-CHF) randomized with $C D$ at discharge from the hospital were more likely to die in the first 3 months after surgery $(p=0.02)$.

Thus, when faced with CD studies with different results, it is difficult to know whether the differences are significant or simply related to when and how cognitive function was determined after cardiac surgery.

\section{Conclusions}

1. It was found that the existing cognitive disorders before surgery were registered in $66.1 \%$ of patients, mostly among the age group 60-74 years and had no sex difference.

2. It is established that in the early postoperative period there is a significant deterioration of cognitive functions in patients after cardiac surgery (on the 3rd day - in $80.4 \%$, on the 7 th day - in $78.6 \%$ of patients, respectively).

trial. European journal of heart failure, 15(6), 699-707. doi: 10.1093/eurjhf/hft020

[10] Itagaki, A., Sakurada, K., Matsuhama, M., Yajima, J., Yamashita, T., \& Kohzuki, M. (2020). Impact of frailty and mild cognitive impairment on delirium after cardiac surgery in older patients. Journal of cardiology, 76(2), 147-153. doi: 10.1016/ j.jjcc.2020.02.007

[11] Julayanont, P., Brousseau, M., Chertkow, H., Phillips, N., \& Nasreddine, Z. S. (2014). Montreal Cognitive Assessment Memory Index Score (MoCA-MIS) as a Predictor of Conversion from Mild Cognitive Impairment to A Izheimer's Disease. Journal of the American Geriatrics Society, 62(4), 679-684. doi: 10.1111/jgs. 12742

[12] Knipp, S. C., Matatko, N., Wilhelm, H., Schlamann, M., Thielmann, M., Losch, C., ... \& Jakob, H. (2008). Cognitive outcomes three years after coronary artery bypass surgery: relation to diffusion-weighted magnetic resonance imaging. The Annals of thoracic surgery, 85(3), 872-879. doi: 10.1016/ j.athoracsur.2007.10.083

[13] Monk, T. G., Weldon, B. C., Garvan, C. W., Dede, D. E., Van Der Aa, M. T., Heilman, K. M., \& Gravenstein, J. S. (2008). Predictors of cognitive dysfunction after major noncardiac surgery. The Journal of the American Society of Anesthesiologists, 108(1), 18-30. doi: 10.1097/01.anes.0000296071.19434.1e

[14] Newman, M. F., Kirchner, J. L., Phillips-Bute, B., Gaver, V., Grocott, H., Jones, R. H., ... \& Blumenthal, J. A. (2001). Longitudinal assessment of neurocognitive function after coronary-artery bypass surgery. New England Journal of Medicine, 344(6), 395-402. doi: 10.1056/ NEJM200102083440601

[15] Newman, M. F., Mathew, J. P., Grocott, H. P., Mackensen, G. B., Monk, T., Welsh-Bohmer, K. A., ... \& Mark, D. B. (2006). Central nervous system injury associated with cardiac surgery. The Lancet, 368(9536), 694-703. doi: 10.1016/S01406736(06)69254-4

[16] Nguyen, Q., Uminski, K., Hiebert, B. M., Tangri, N., \& Arora, R. C. (2018). Midterm outcomes after postoperative delirium on cognition and mood in patients after cardiac surgery. The Journal of thoracic and cardiovascular surgery, 155(2), 660667. doi: 10.1016/j.jtcvs.2017.09.131

[17] Ottens, T. H., Dieleman, J. M., Sau?r, A. M. C., Peelen, L. M., Nierich, A. P., de Groot, W. J., ... \& DExamethasone for Cardiac Surgery (DECS) Study Group. (2014). Effects of 
dexamethasone on cognitive decline after cardiac surgery: a randomized clinical trial. Anesthesiology, 121(3), 492-500. doi: 10.1097/ALN.0000000000000336

[18] Rasmussen, L. S., Larsen, K., Houx, P., Skovgaard, L. T., Hanning, C. D., Moller, J. T., \& ISPOCD group. (2001). The assessment of postoperative cognitive function. Acta Anaesthesiologica Scandinavica, 45(3), 275-289. doi: 10.1034/ j.1399-6576.2001.045003275.x

[19] Romero, J. R., Beiser, A., Seshadri, S., Benjamin, E. J., Polak, J. F., Vasan, R. S., ... \& Wolf, P. A. (2009). Carotid artery atherosclerosis, MRI indices of brain ischemia, aging, and cognitive impairment: the Framingham study. Stroke, 40(5), 1590-1596. doi: 10.1161/STROKEAHA. 108.535245

[20] Rovio, S. P., Pahkala, K., \& Raitakari, O. T. (2019). Cognitive Decline Before and After Incident Coronary Heart Disease: Opportunity to Intervene Cognitive Function Trajectories. Journal of the American College of Cardiology, 73(24), 30513053. doi: 10.1016/j.jacc.2019.04.020

[21] Rudolph, J. L., Schreiber, K. A., Culley, D. J., McGlinchey, R. E., Crosby, G., Levitsky, S., \& Marcantonio, E. R. (2010). Measurement of post-operative cognitive dysfunction after cardiac surgery: a systematic review. Acta Anaesthesiologica Scandinavica, 54(6), 663-677. doi: 10.1111/j.13996576.2010.02236.x

[22] Sauer, A. C., Veldhuijzen, D. S., Ottens, T. H., Slooter, A. J. C., Kalkman, C. J., \& Van Dijk, D. (2017). Association between delirium and cognitive change after cardiac surgery. BJA: British Journal of Anaesthesia, 119(2), 308-315. doi: 10.1093/ bja/aex053

[23] Selnes, O. A., Grega, M. A., Bailey, M. M., Pham, L. D., Zeger, S. L., Baumgartner, W. A., \& McKhann, G. M. (2008). Cognition 6 years after surgical or medical therapy for coronary artery disease. Annals of neurology, 63(5), 581-590. doi: 10.1002/ ana.21382

[24] Silverstein, J. H. (2014). Cognition, anesthesia, and surgery. International anesthesiology clinics, 52(4), 42-57. doi: 10.1097/AIA.0000000000000032

[25] Vogels, R. L., Oosterman, J. M., Van Harten, B., Scheltens, P., Van Der Flier, W. M., Schroeder-Tanka, J. M., \& Weinstein, H. C. (2007). Profile of cognitive impairment in chronic heart failure. Journal of the American Geriatrics Society, 55(11), 17641770. doi: 10.1111/j.1532-5415.2007.01395.x

[26] Wang, W. C., Dew, I. T., \& Cabeza, R. (2015). Age-related differences in medial temporal lobe involvement during conceptual fluency. Brain research, 1612, 48-58. doi: 10.1016/ j.brainres.2014.09.061

[27] Williams, U. E., Owolabi, M. O., Ogunniyi, A., \& Ezunu, E. O. (2013). Prevalence and pattern of neurocognitive impairment in Nigerians with stages 3 to 5 chronic kidney disease. International Scholarly Research Notices, 2013. doi: 10.1155/ 2013/374890 